Journal of Applied Fluid Mechanics, Vol. 15, No. 2, pp. 537-549, 2022.

Available online at www.jafmonline.net, ISSN 1735-3572, EISSN 1735-3645.

https://doi.org/10.47176/jafm.15.02.32987

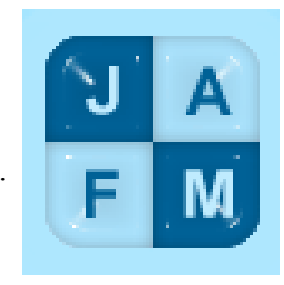

\title{
Generation of Stable Linear Waves in Shallow Water in a Numerical Wave Tank
}

\author{
S. S. Yadav and P. DebRoy ${ }^{\dagger}$ \\ Department of Mechanical Engineering, National Institute of Technology, Silchar, Assam-788010, India \\ †Corresponding Author Email: pdebroy@mech.nits.ac.in
}

(Received May 9, 2021; accepted October 10, 2021)

\begin{abstract}
This paper aims to investigate numerically linear stable waves at low wave steepness in shallow water using ANSYS Fluent software. The authors mainly determined how, when, and where a linear wave will reach its stable state in shallow water. The finite volume method is used to solve the Navier-Stokes equations. The inflow velocity method and the Dirichlet boundary condition are used to generate a suitable linear wave. Numerical damping is used at the end of the tank to reduce the reflection of the wave. The accuracy and stability of the waves are judged under wave height variation between the CFD results and the analytical results. The test has been conducted in four different cases (Case 1, Case 2, Case 3, and Case 4). Wave evolution and particle velocity are obtained in the velocity field to understand the wave stability in the numerical wave tank. Numerical data are captured from the free surface to compare the surface profile and wave velocity. The results have revealed that the accuracy, stability, and consistency of the linear waves are in good agreement with the analytical solution. The relative error between the two results is $1.43 \%$ for Case 3 . This research is a highly relevant source of information in realistic wave generation to design various practical systems such as wave energy converters, offshore marine structures, and many ocean engineering problems.
\end{abstract}

Keywords: Numerical wave tank; Stable wave generation; Inflow method; Linear wave; Shallow water.

\section{NOMENCLATURE}

$\begin{array}{ll}d & \text { water depth } \\ H & \text { wave height } \\ H / L & \text { wave steepness } \\ k & \text { wavenumber } \\ L & \text { wavelength } \\ p & \text { pressure } \\ T & \text { time period } \\ t & \text { time }\end{array}$

\section{INTRODUCTION}

The critical point in designing marine structures is to test the laboratory model for understanding the wave-body interaction. Inevitably laboratory experiments in a wave tank become more expensive, followed by tests on scale models. However, the study for a relatively quick test became inexpensive, numerically by ANSYS FLUENT software and the VOF method. This point guides the researchers that using a numerical model can represent the real-life environment. Here, we have developed a Numerical

$\begin{array}{ll}u, w & \mathrm{x} \text { and } \mathrm{z} \text { - velocity component } \\ x, z & \text { longitudinal and transverse coordinate } \\ \alpha_{q} & \text { volume fraction function } \\ \eta & \text { surface profile } \\ v & \text { kinematic viscosity } \\ \omega & \text { angular frequency } \\ \phi & \text { potential function } \\ \rho & \text { density }\end{array}$

wave tank (NWT) using CFD software. The wave is generated at the inlet of the tank and reduces its energy at the damping zone.

Another critical point in modeling wave-body interactions in shallow water is the accurate generation of appropriate waves. Otherwise, the model cannot perform correctly. Thus, the generated linear wave is required to verify the stability before testing wave structure interaction. Generally, models are tested in shallow water using solitary wave and cnoidal waves (e.g., Wu et al. 2012, 2014b; Wu and Hsiao 2013, 2017; Jensen et al. 2003) experimentally 
developed wave runup on $10.54^{\circ}$ beach angle to study the wave velocity and surface elevation. Lu and $\mathrm{Yu}(2008)$ numerically explored solitary waves below water using Boussinesq equations. Refer to the graph (Le Méhauté 1976, Fig. 4) shown by red zone; linear wave theory applied to test the model, and we have focused our goal in this zone to generate an accurate, stable linear wave in shallow water.

The more seminal works are: Benjamin and Lighthill (1954) investigated the new presentation of the Cnoidal Waves theory for a long wave. Leng and Chanson (2017) experimentally studied the unsteady velocity profile in bores and systematically performed positive surges by the new velocity profiling measurements under controlled flow conditions. Leng et al. (2018a) studied the flow field and turbulence characteristics of tidal bores using computational fluid dynamics (CFD). Leng et al. (2018b) studied the tidal bore flow of the Garonne River at unsteady and rapidly varied conditions. Gualtieri and Chanson (2012); Gualtieri and Chanson (2011) experimentally investigated the positive surge in an open channel in two parts. Part 1: to understand the basic flow patterns and wave attenuation, and Part 2: compared the results with literature theories.

Various types of wave theories were used in shallow water at different times by many authors. Among them, Boussinesq first-order solitary waves are commonly used (Boussinesq (1871)). Goring (1978) experimentally generated solitary waves in a wave basin, which validated the theory of Boussinesq (1871). Wu et al. (2014a) various solitary wave theories are implemented to solve nonlinear potential equations after the numerical validation of the Goring (1978) method. Wu et al._2016 has been implemented this concept in a wave tank. Huang and Dong (2001) generated solitary waves in a wave flume by piston-type wavemaker. Keulegan (1948) and Mei (1983) noticed that solitary wave damped out as it propagates by frictional \& viscous effect. Farhadi et al. (2016) experimentally developed the study done by Wu et al. (2014a) accurately in a laboratory using a piston-type wavemaker. In the present study, the inflow method generates the wave in a numerical wave tank.

Seiffert et al. (2014) developed the various solitary wave theories in the laboratory by different types of wavemakers and found no significant differences in the results. Liang et al. (2010) use the finite element method (FEM) to generate irregular waves by the piston-type wavemaker. Lal and Elangovan (2008) numerically simulated linear waves by flap type wavemaker using finite volume method.

The past works of literature explain periodic wave theory (Grilli et al. 1997; Liu et al. 2000; Guyenne and Grilli 2006) and the shallow wave ( $\mathrm{Li}$ and Raichlen 2001; Lynett et al. 2002; Lu and Yu 2008). Grilli et al. (1997) numerically study the solitary waves systematically at various beach angles. Liu et al. (2000) explored the end wall reflection of the solitary wave using the BIE method. Li and Raichlen (2001) investigated the runup of the solitary wave at shallow water. Lynett et al. (2002) numerically investigated wave runup \& rundown using Boussinesq equations by developing the moving boundary method. A numerical model based on RANS equations and the $\mathrm{k}-\varepsilon$ model was developed by Lin and Liu (1998) and Peng and Yijun (2006) to study the periodic wave. Yang et al. (2019) performed a 3-D numerical simulation to analyze the fluid characteristics of pitching sloshing under microgravity using OpenFOAM software. The effect of liquid height has been analyzed to check the behavior of natural frequency. The authors suggested efficient liquid management in space. Cornejo and Sepulveda (2016) modeled a midlatitude small-scale upper oceanfront using three different methods. Wijetunge (2010) studied the spatial distribution of inundation nearly by $2 \mathrm{~km}$ long dune on the coast of Sri Lanka.

The present numerical work mainly uses Dirichlet boundary conditions at the no-slip plane to generate stable linear waves accurately in shallow water. The accuracy and stability are judged based on wave height variations of the results. The test has conducted in four different cases (Case 1, Case 2, Case 3, and Case 4). Generally, a wave changes its properties when it enters a wave basin or in an NWT due to the viscous effect of water. However, the issue of how, when, and where a linear wave will reach its stable state in shallow water is still unsolved. It would be a valuable guideline to engineers for making a model where linear waves will be stable at a given wave height from the wavemaker. Wave evolution and particle velocity are obtained in the velocity field to understand the wave stability in the numerical study. Numerical model data are captured from the free surface to compare surface profile and wave velocity with the analytical data.

\section{Methodology}

\subsection{Numerical Model}

The computational domain of NWT is a rectangle $\left(l_{x} \times l_{z}\right)$, with the left end is the wave generating zone $\left(l_{x l}=25 \mathrm{~m}\right)$, and the right part of the domain is the damping zone $\left(l_{x 2}=40 \mathrm{~m}\right)$, and the middle portion considers as a working zone. Two different water depths, i.e., $d=1 \mathrm{~m}$ and $0.5 \mathrm{~m}$, are considered. Cartesian coordinate $x-z$ is the vertical plane on the fluid surface. The $x$-axis is considered along with the propagation of the wave, and the $z$-axis is vertically upward from SWL. The desire linear wave of wave heights $H=0.016 \mathrm{~m}$, and $0.02 \mathrm{~m}$ for $T=5.82 \mathrm{~s}$ and $H=0.031 \mathrm{~m}$, and $0.04 \mathrm{~m}$ for $T=8.01 \mathrm{~s}$ are generated at $x=0$ and flow in the $x$-direction. The free surface oscillates along with the $z$-axis, and the flow effect is neglected in the y-direction. The upper boundary is the atmosphere of the NWT. The bottom and right walls of the numerical domain are set as no-slip boundary conditions. No slip means no relative motion between fluid and solid walls at the contact point. VOF method is used in the simulation to capture the motion of two phases. The geometry of the numerical wave tank is shown in Fig. 1.

The rectangular grid is discretized in the computational domain. Grid with approximately 


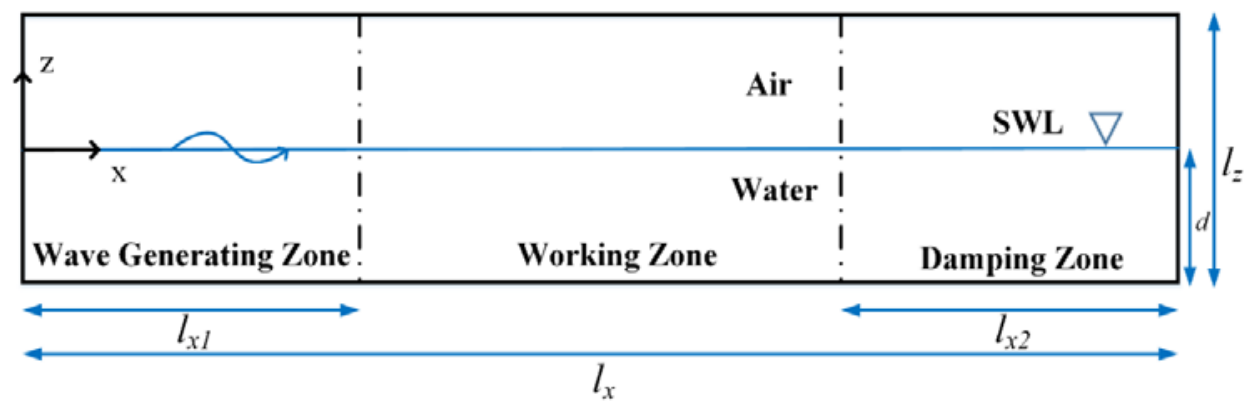

Fig. 1. Schematic diagram of the numerical wave tank.

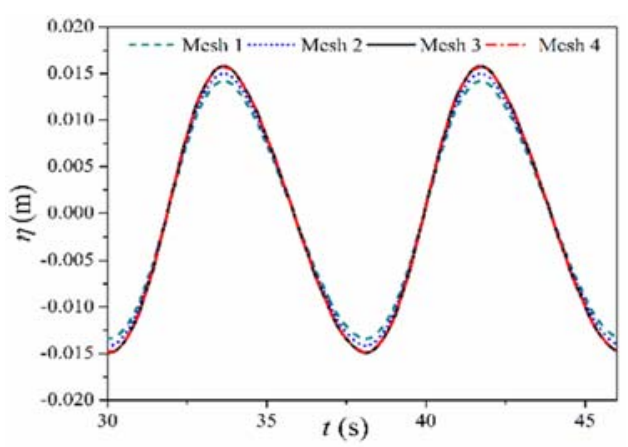

Fig. 2. Surface elevation $(\eta)$ versus time at $H=0.031 \mathrm{~m}$ for the independence test on various mesh sizes.

351651 nodes has been tested for investigating the numerical results. To analyze the free surface's wave behavior more accurately, mesh refinement has needed from the bottom of the water to the mean water level's vicinity, as shown in Fig. 3. The size of the mesh gradually increases towards the end of the NWT to produce a damping zone.

The grid independence test has been performed to check the grid system in the present numerical study. Table 2 shows the four different meshes for the convergence test. Mesh sizes decrease gradually from Mesh 1 to Mesh 4. The nodes are 151151, 241401, 351651, and 421781 are used for grid independence tests. For the independence test, surface elevation $(\eta)$ has been compared for the four meshes at $H=0.031 \mathrm{~m}$ (Fig. 2). It has been observed from the convergent results that the surface elevation obtained from Mesh 3 and Mesh 4 are very close, and the difference of numerical results of Mesh 3 and Mesh 4 is $0.00015 \%$. Therefore, the grid size of Mesh 3 is sufficient to achieve accuracy, and Mesh 3 is adopted for further simulation.

The system's specification at which simulation has run is an Intel(R) Xeon(R) W-2155CPU@3.30GHz $3.31 \mathrm{GHz}$ processor and a $64.0 \mathrm{~GB}$ RAM. A simulation is performed based on Navier-Stokes Equations (NSE) with a viscous model. The firstorder implicit scheme and a second-order upwind scheme are used here for discretization. The time step size is set at $0.01 \mathrm{~s}$, the number of time steps is selected in 5000, and the maximum iteration is taken as 20 . The Courant number is set at 0.25 for stability. According to the above assumptions, the total simulation took $24 \mathrm{hrs}$ to solve the problem.

\subsection{Geometry of Damping}

The absorption of an incident wave by arranging a damping zone at the end of the NWT is the essential factor; otherwise, the waves will reflect from the tank's end and disturb the simulation. Different authors proposed different methods in their literature:

- Simulation time is required to control that the generated wave does not reach the tank's end.

- Increases the mesh sizes for reducing wave energy at the endpoint of the wave tank.

- Beach slope implementation (Saincher and Banerjee 2015)

-Increase the tank length to reduce the reflection of the wave.

-Implementation of damping.

In this work, we have used three methods to dissipate the wave energy: (1) mesh size is increased at the end of the tank to dissipate wave's energy, (2) Size of the tank length increases, for reducing the wave reflection from the affecting area, and (3) creating a damping zone. Wave tank height is increased to $1 \mathrm{~m}$ above the SWL to prevent the circulation of air.

\subsection{Governing equations}

The water wave propagation in a wave tank is modeled by ANSYS FLUENT software. The volume of fluid (VOF) method is used to solve the problem. The flow behavior is assumed to be unsteady, incompressible, irrotational flow, without surface tension, and with atmospheric pressure $p_{a}=0$. Navier-Stokes equation (NSE) is used based on these assumptions to investigate the generated linear waves' stability and accuracy. The governing equations are mass continuity \& momentum equations as described below:

$$
\begin{aligned}
& \frac{\partial u}{\partial x}+\frac{\partial w}{\partial z}=0 \\
& \frac{\partial u}{\partial t}+u \frac{\partial u}{\partial x}+w \frac{\partial u}{\partial z}=-\frac{1}{\rho} \frac{\partial p}{\partial x}+v\left[\frac{\partial^{2} u}{\partial x^{2}}+\frac{\partial^{2} u}{\partial z^{2}}\right]
\end{aligned}
$$




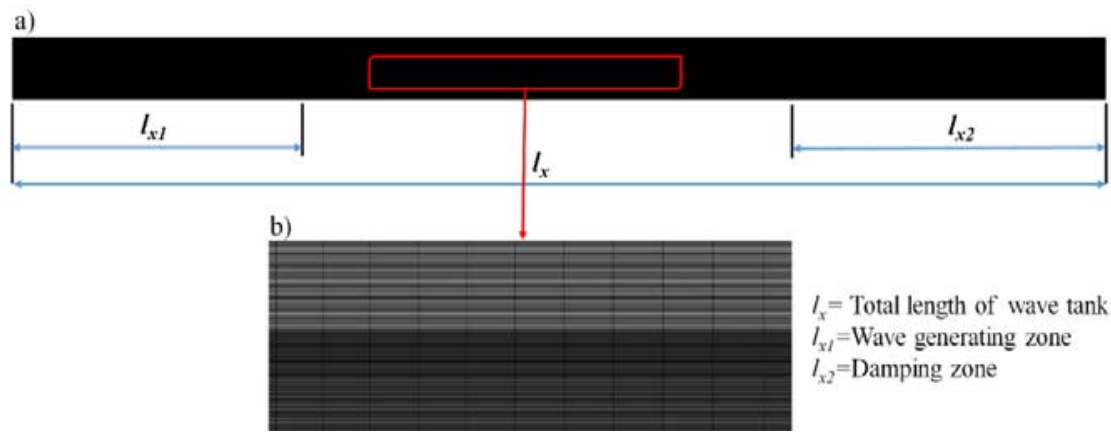

Fig. 3. Computational mesh in the numerical domain.

Table 1 Wave parameters used in the present study.

\begin{tabular}{|c|c|c|c|c|c|c|c|c|c|}
\hline Case & $\begin{array}{c}\text { Tank } \\
\text { length } \\
l_{x}(\mathrm{~m})\end{array}$ & $\begin{array}{c}\text { Time } \\
\text { period } \\
T(\mathrm{~s})\end{array}$ & $\begin{array}{c}\text { Water } \\
\text { depth } \\
d(\mathrm{~m})\end{array}$ & $\begin{array}{c}\text { Wave } \\
\text { length } \\
L(\mathrm{~m})\end{array}$ & $\begin{array}{c}\text { Wave } \\
\text { height } \\
H(\mathrm{~m})\end{array}$ & $(d / L)$ & $(H / L)$ & $d / g T^{2}$ & $H / g T^{2}$ \\
\hline \multicolumn{2}{|c|}{ On the surface, $z=0$} \\
$\begin{array}{c}\text { Case } \\
1\end{array}$ & 100 & 5.82 & 0.5 & 12.8687 & 0.016 & 0.038 & 0.00124 & 0.00150 & $4.8 \times 10^{-5}$ \\
\hline $\begin{array}{c}\text { Case } \\
2\end{array}$ & 100 & 5.82 & 0.5 & 12.8687 & 0.02 & 0.038 & 0.00155 & 0.00150 & $6.0 \times 10^{-5}$ \\
\hline \multicolumn{2}{|c|}{ On the surface, $z=0$} \\
$\begin{array}{c}\text { Case } \\
3\end{array}$ & 100 & 8.01 & 1 & 25.001 & 0.031 & 0.04 & 0.00123 & 0.00158 & $4.9 \times 10^{-5}$ \\
\hline $\begin{array}{c}\text { Case } \\
4\end{array}$ & 100 & 8.01 & 1 & 25.001 & 0.04 & 0.04 & 0.00159 & 0.00158 & $6.3 \times 10^{-5}$ \\
\hline
\end{tabular}

Table 2 Mesh size parameters.

\begin{tabular}{|c|c|c|c|}
\hline Mesh & $\Delta x(\mathrm{~m})$ & $\Delta z(\mathrm{~m})$ & Nodes \\
\hline 1 & 0.100 & 0.013 & 151151 \\
\hline 2 & 0.083 & 0.010 & 241401 \\
\hline 3 & 0.071 & 0.008 & 351651 \\
\hline 4 & 0.066 & 0.007 & 421781 \\
\hline
\end{tabular}

$$
\frac{\partial w}{\partial t}+u \frac{\partial w}{\partial x}+w \frac{\partial w}{\partial z}=-\frac{1}{\rho} \frac{\partial p}{\partial z}+v\left[\frac{\partial^{2} w}{\partial x^{2}}+\frac{\partial^{2} w}{\partial z^{2}}\right]
$$

where $u$ and $w$ are the velocity $\left[\mathrm{m} \mathrm{s}^{-1}\right] ; t=$ time [s]; $p=$ pressure $[\mathrm{Pa}] ; \rho=$ density $\left[\mathrm{kg} \mathrm{m}^{-3}\right]$ which varies over the air and water interface, and $v$ is the kinetic viscosity $\left[\mathrm{m}^{2} \mathrm{~s}^{-1}\right]$.

In the present study, the two fluids' interface has been modeled by the VOF method (Hirt and Nichols 1981). The term $\alpha_{q}$ is the volume fraction. Accordingly, there can be three possible conditions. Such that $\alpha_{q}=1, \alpha_{q}=0$ and $0<\alpha_{q}<1$. Subscript, $q=1$ or 2 means only two phases: air and water. The following equations are used to determine $\alpha_{q}$ :

$$
\begin{aligned}
& \frac{\partial \alpha_{q}}{\partial t}+\nabla \cdot\left(\alpha_{q} \bar{V}\right)=0 \\
& \sum_{q=1}^{2} \alpha_{q}=1
\end{aligned}
$$

Where $\bar{V}=$ velocity vector. Equation (6) represents the mixture density of air and water.

$\rho=\alpha_{q} \rho_{w}+\left(1-\alpha_{q}\right) \rho_{a}$

Where $\rho_{a}$ and $\rho_{w}$ are the density of air and water, the density of air and water have been taken as $\rho_{a}=1.225$ $\mathrm{kg} / \mathrm{m}^{3}, \rho_{w}=998.2 \mathrm{~kg} / \mathrm{m}^{3}$, respectively.

\section{THEORETICAL FORMULATION}

\subsection{Linear wave theory}

Here, the linear wave theory of finite-amplitude (Dean and Dalrymple 1984) is used for validation. Equation (7) represents the free surface profile as follows:

$$
\eta(x, t)=-\left.\frac{1}{g} \frac{\partial \phi}{\partial t}\right|_{z=0}=\frac{H}{2} \cos (k x-\omega t)
$$

where $H=$ wave height $[\mathrm{m}]$. Another parameter $\omega(=2 \pi / T)$ is the angular frequency of the wave 


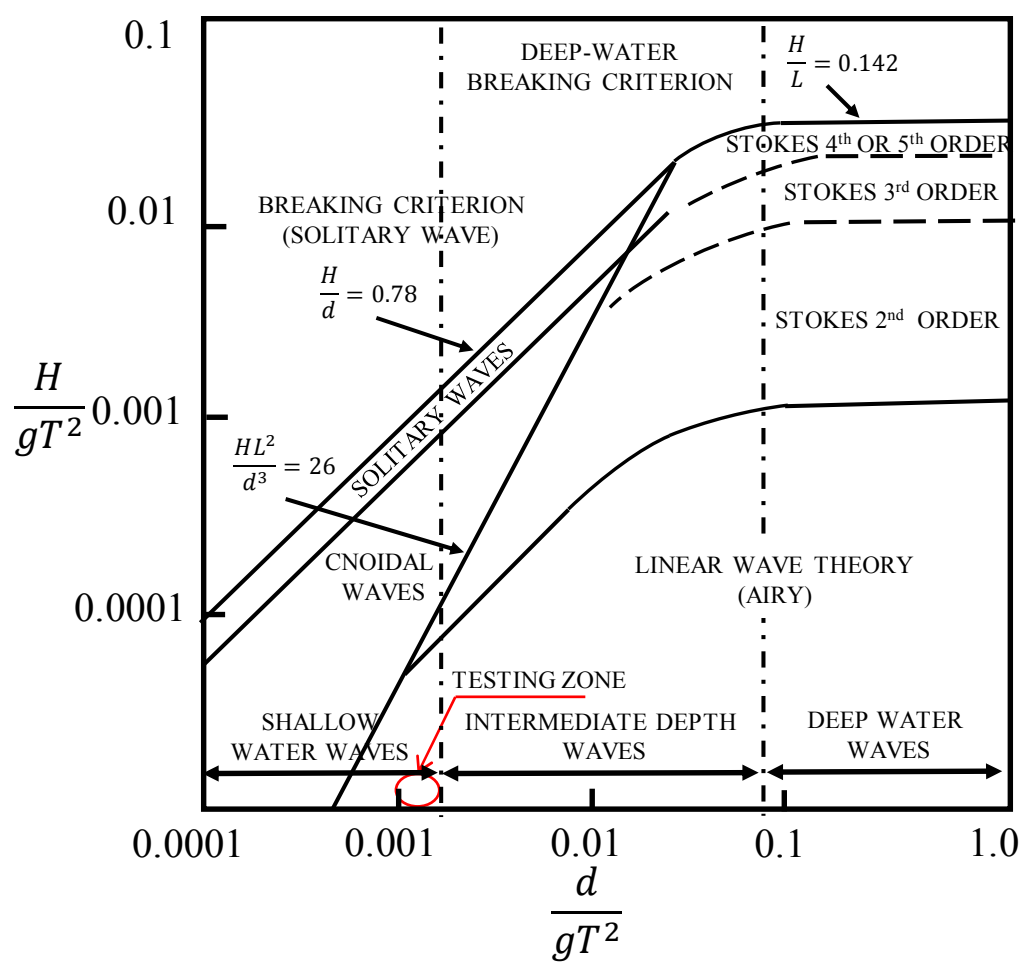

Fig. 4. Limits of validity for various wave theories ( Le Méhauté 1976).

[ $\left.\mathrm{rad} \mathrm{s}^{-1}\right]$, and the wave number $k(=2 \pi / L)$ satisfies the dispersion relation given in Eq. (8). Here, $d$ is the water depth [m], and $L$ is the wavelength [m]. The dispersion relation is given by:

$\omega^{2}=k g \tanh (k d)$

Equations (9) and (10) gives the local velocity in the horizontal and vertical directions, respectively, which are obtained by partial derivatives of the potential function $\phi$.

$u=-\frac{\partial \phi}{\partial x}=\frac{H}{2} \frac{g k}{\omega} \frac{\cosh k(z+d)}{\cosh k d} \cos (k x-\omega t)$

$w=-\frac{\partial \phi}{\partial z}=\frac{H}{2} \frac{g k}{\omega} \frac{\sinh k(z+d)}{\cosh k d} \sin (k x-\omega t)$

\section{Results AND Discussions}

This study focused on generating an accurate, stable linear wave in shallow water at a constant water depth. A numerical wave tank model has been developed based on CFD code ANSYS Fluent software to achieve this target. VOF method is used to generate the linear wave. The generating wave's accuracy and stability are judged under wave height variation between the CFD and the analytical results. Figure 4 shows a test zone by a red closed area of the linear wave theory in the shallow water. The graph is plotted for 2-D periodic waves, but it indicates any water waves. The graph is lying under the standard line of breaking waves. Corresponding coordinates of the red closed area where the test has been conducted are shown in Table 1.

\subsection{Validation of LWT with CFD wave}

The numerical method is required validation for the analysis. Figures 5 and 6 show the comparative study of surface profile between CFD and analytical results at $x=30 \mathrm{~m}$. It has been demonstrated that after nearly four periods for Fig. 5 and after almost three periods for Fig. 6, the wave approaches its steady profile, and the wave becomes matches almost with the analytical results at the time $t=25 \mathrm{~s}$ in both the depth of water.

\subsection{Study on surface elevation}

In this section, surface elevations of linear wave theory (LWT) have been tested at sallow water under four different wave steepness $(H / L=0.00124$, $0.00155,0.00123$, and 0.00159 ) conditions for the wave period $T=5.867 \mathrm{~s}$ and $8.01 \mathrm{~s}$, respectively. Both the analytical (obtained from Eq. 7) and numerical results have been depicted comparatively. To carefully examine the accuracy, consistency, and stability of the proposed linear wave in a numerical wave tank, three probes are placed from the wavemaker at $x=30 \mathrm{~m}, x=37 \mathrm{~m}$, and $x=45 \mathrm{~m}$ to record the surface elevation of the free surface. Figure 7 (a-c) shows the time history of surface elevation $(\eta)$ against the time $(t)$ between the time $t=25 \mathrm{~s}$ to $50 \mathrm{~s}$. In terms of wave height, Fig. 7(c) has shown that at $x=45 \mathrm{~m}$, the simulation results slightly mismatched with those at $x=30 \mathrm{~m}$ and $x=37 \mathrm{~m}$ and closely with the theoretical results. The wave heights obtained from the CFD simulation results are slightly 


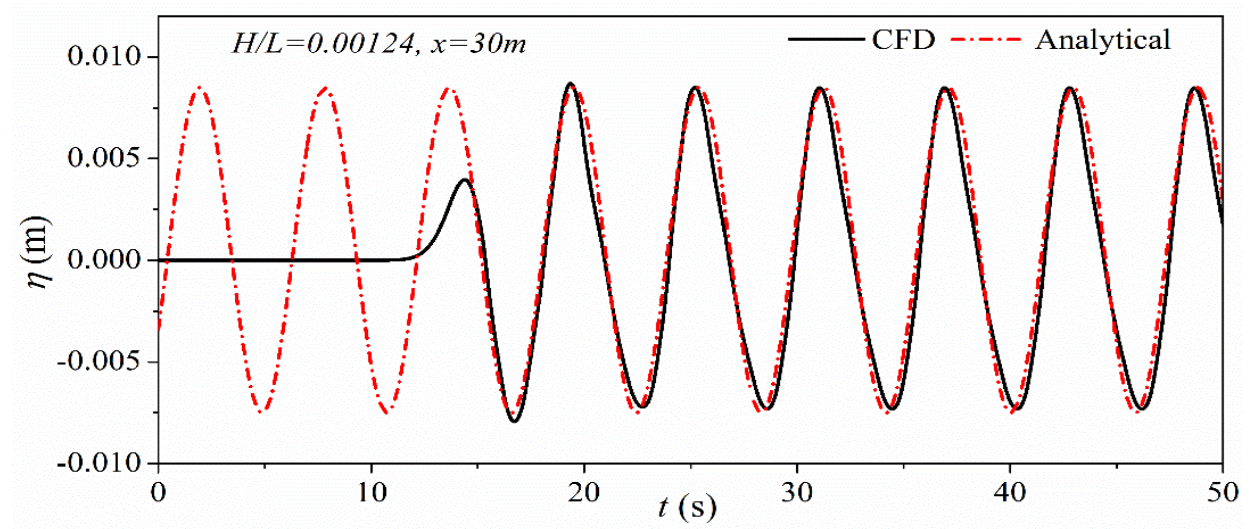

Fig. 5. Comparison of surface elevations of CFD generated wave to a linear wave at $d=0.5 \mathrm{~m}$ for $H=0.016 \mathrm{~m} \& T=5.86 \mathrm{~s}$.

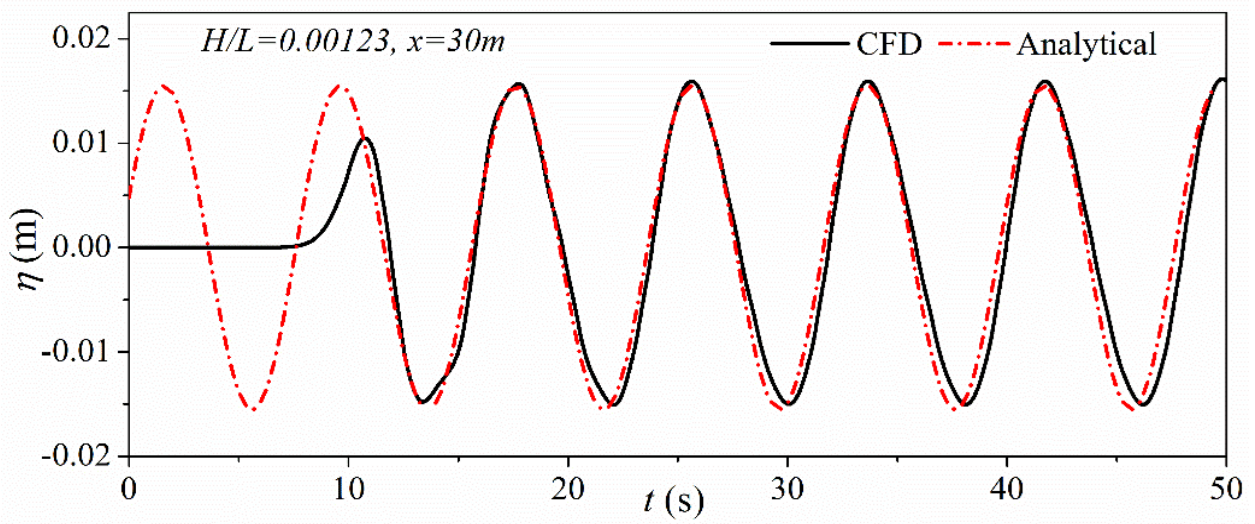

Fig. 6. Comparison of surface elevations of CFD generated wave to a linear wave at $d=1 \mathrm{~m}$ for $H=0.031 \mathrm{~m} \& T=8.01 \mathrm{~s}$.

overpredicted compared with the theoretical result, as shown in Fig. 8(a-c). However, the CFD simulation results are shown in Figs. 7 to 8 nearly agree with the theoretical results.

After completing the previous tests, we considered another wave height, $H=0.031 \mathrm{~m} \& 0.04 \mathrm{~m}$, and water depth $d=1 \mathrm{~m}$. The results obtained from the CFD simulation at three different locations $(x=30 \mathrm{~m}$, $x=37 \mathrm{~m}$, and $x=45 \mathrm{~m}$ ) under the new considerations are presented in Fig. 9-10. It has been observed from Fig. 9(a) (Case 3) that the simulation results are in good agreement with the analytical results at $x=30 \mathrm{~m}$. It has also been shown that almost constant wave crests and troughs with the theoretical results indicated no significant wave reflections. It has also been shown in Fig. 10(a) that the wave trough does not match the theoretical results at $x=30 \mathrm{~m}$. Therefore, we can conclude that the linear wave reaches its stable state at $x=30 \mathrm{~m}$ from the wavemaker for the wave steepness $H / L=0.00123$ between the time $t=25 \mathrm{~s}$ to $50 \mathrm{~s}$. It can also be concluded that the accuracy, stability, and consistency of the linear wave theory in shallow water in a proposed NWT can satisfy the need to study the problem.

\subsection{Study on horizontal velocity}

In this section, we have discussed the horizontal velocity $(u)$ of water on the free surface $(z=0)$ at two horizontal locations $(x=30 \mathrm{~m}$ and $37 \mathrm{~m})$ in the wave tank, as shown in Figs. 11-14. The observation data were carefully recorded. It has shown in Figs. 11(ab) for Case 1 that CFD results and the theoretical results are not perfectly matching at the trough, and the graph starts double pick at the trough from $x=30 \mathrm{~m}$. It becomes more predominant at $x=37 \mathrm{~m}$. Figure 13(a) (Case 3) has shown an excellent matching between simulated horizontal velocity $(u)$ with theoretical results at $x=30 \mathrm{~m}$. It has further been observed in Fig. 13(a) (Case 3) that wave crests and troughs are almost at a constant level, with the theoretical results. This observation proved that the linear wave reaches its stable state at $x=30 \mathrm{~m}$ from the wavemaker for the wave steepness $H / L=0.00123$ between the time $t=25 \mathrm{~s}$ to $50 \mathrm{~s}$. Further, we noticed that horizontal velocity $(u)$ depends on the wave height and period. Horizontal velocity shown in Fig. 14 presented a higher speed for the wave height $H=$ $0.04 \mathrm{~m}$ than other wave heights $H=0.016 \mathrm{~m}, 0.020 \mathrm{~m}$, and $0.031 \mathrm{~m}$ shown in Figs. 11-13. 

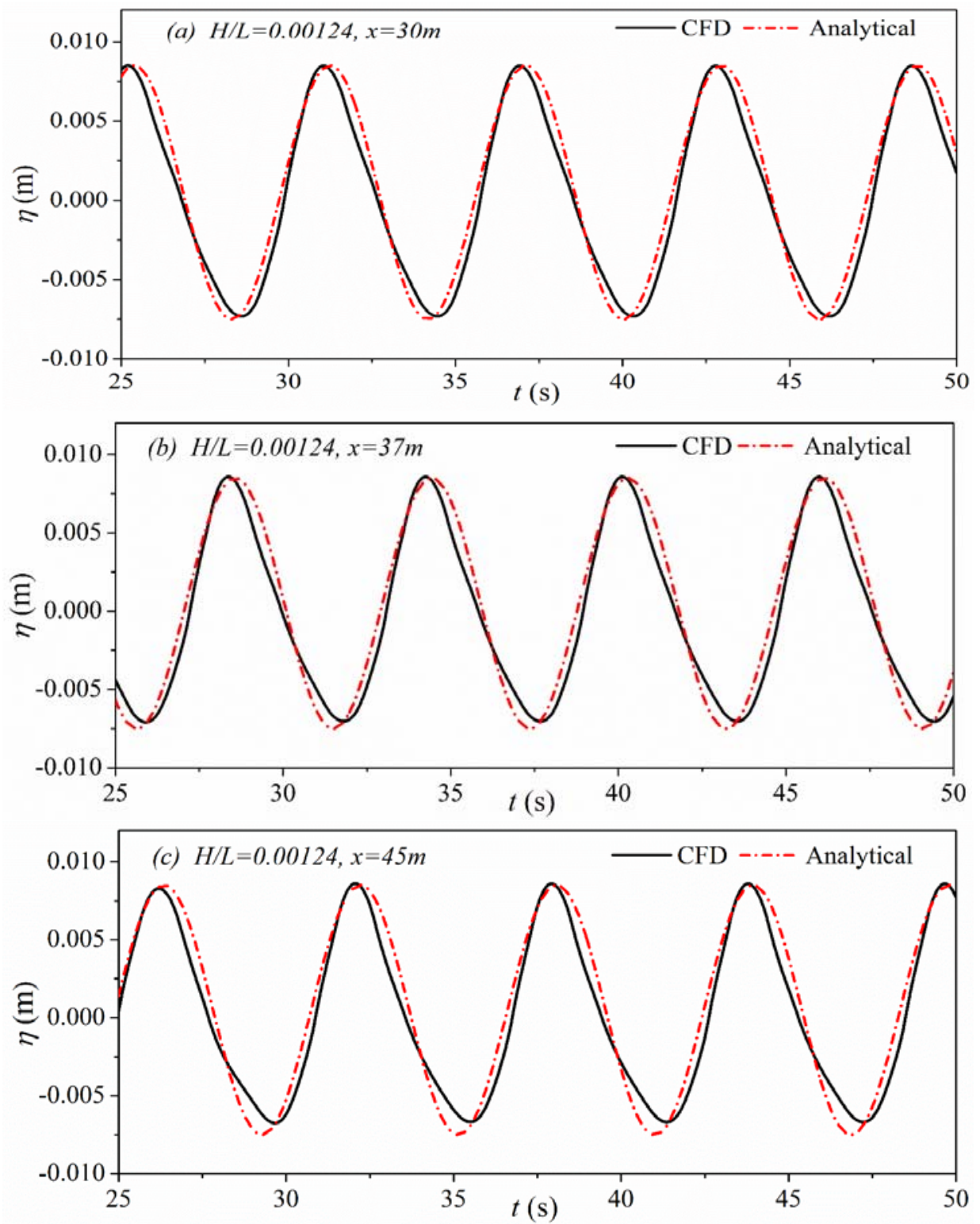

Fig 7. Surface elevation $(\eta)$ versus time for Case 1.

\section{CONCLUSION}

This study investigated the linear wave propagation in shallow water for generating the accurate, stable linear wave at a suitable distance from the wavemaker. The inflow velocity method and the Dirichlet boundary condition are used at the no-slip plane for the generation. The simulation results are compared with the analytical results.

For creating a smooth simulation, we have added wave reflection. For this purpose, three methods have been used: (1) mesh size increases, (2) tank length increases, and (3) creating a damping zone. These measures proved to be very effective.

Two different water depths $(d=1 \mathrm{~m}$ and $0.5 \mathrm{~m})$ are considered to obtain stable linear waves in shallow water. This study also considers other parameters, namely two different wave periods and four different wave heights.

The prime objective of the present work is to generate accurate \& stable linear waves in shallow water. Another objective is to determine the location at which the wave becomes more stable. Accuracy and stability are judged under wave height variation of the results. The test has been conducted in four cases (Case 1, Case 2, Case 3, and Case 4). Wave evolution and particle velocity are obtained in the velocity field to understand the wave stability in the numerical wave tank. Numerical model data are captured from the free surface to compare surface profile and wave velocity with the analytical data. The following conclusions support our results based on the present numerical model. 

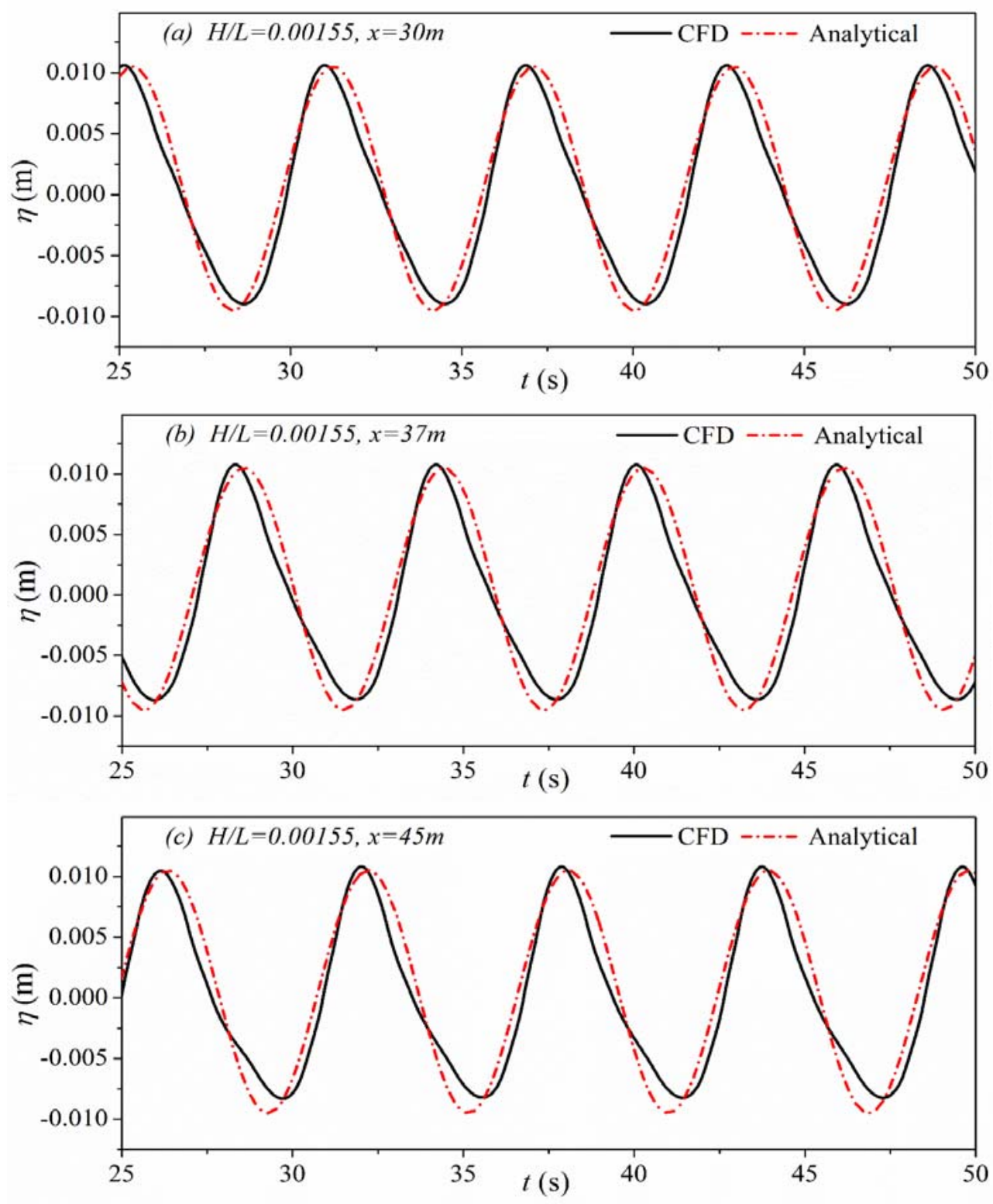

Fig. 8. Surface elevation ( $\eta$ ) versus time for Case 2.

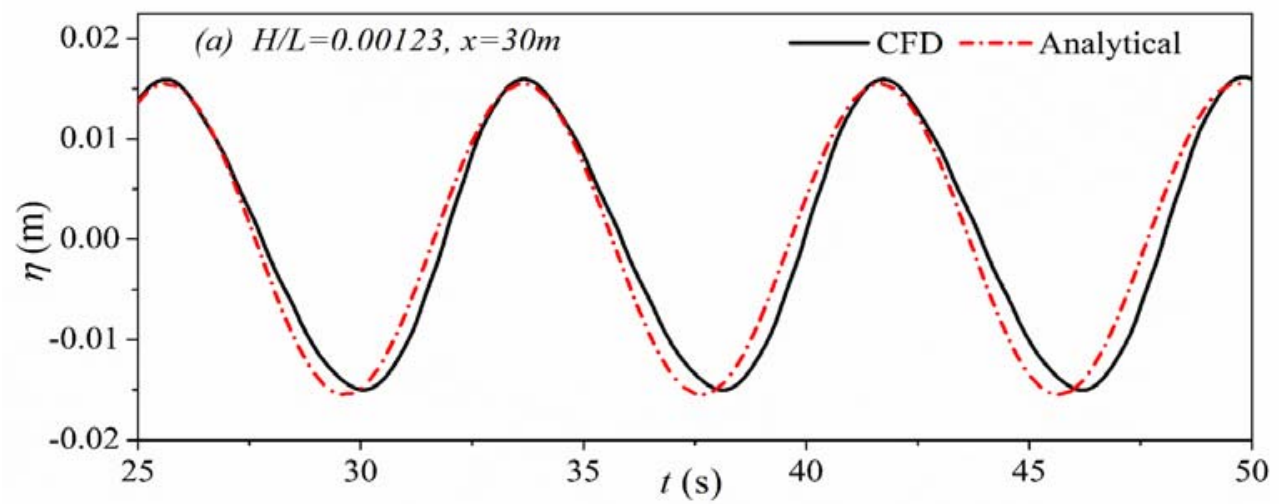


S. S. Yadav and P. DebRoy / JAFM, Vol. 15, No. 2, pp. 537-549, 2022.
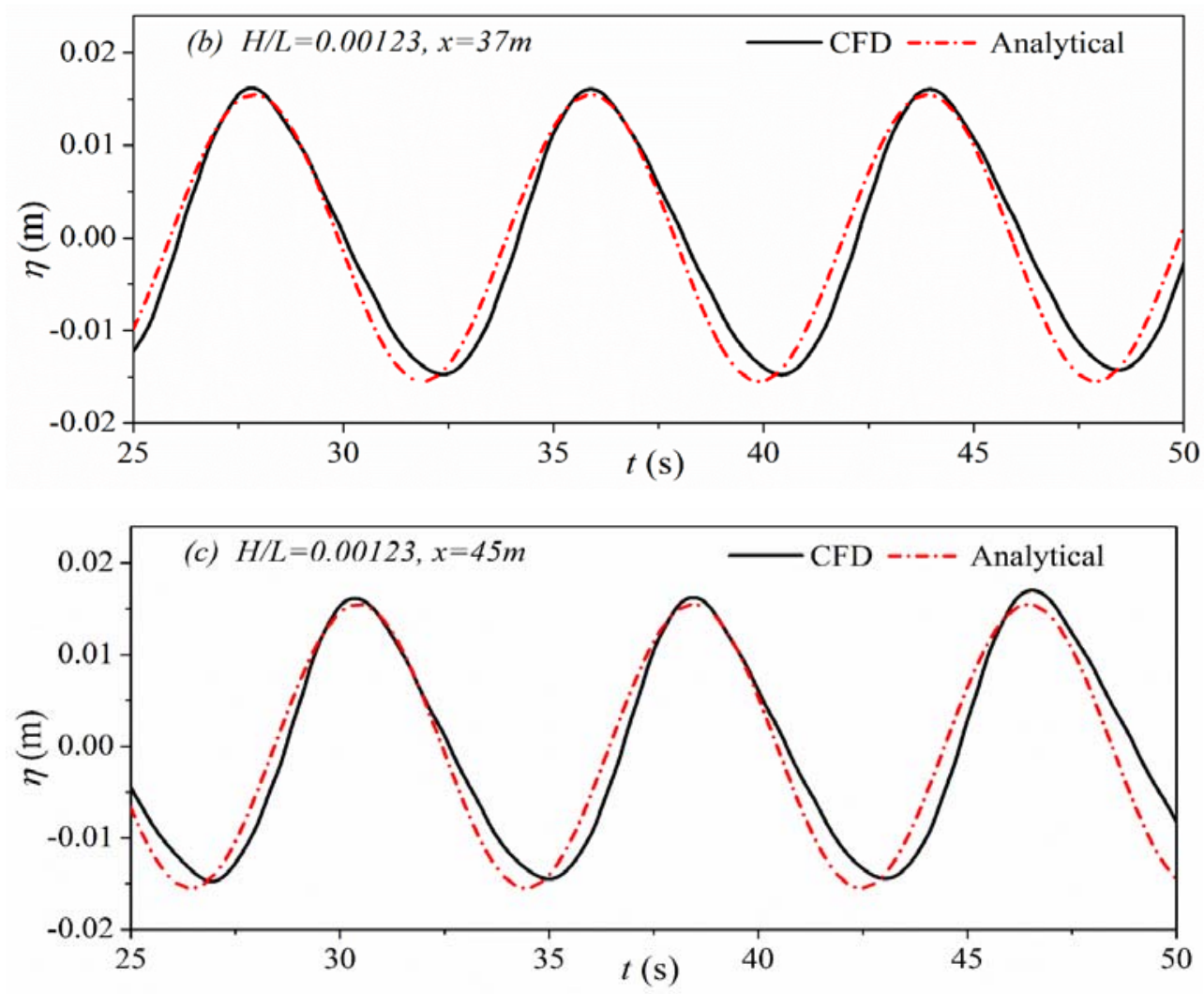

Fig. 9. Surface elevation ( $\eta$ ) versus time for Case 3.
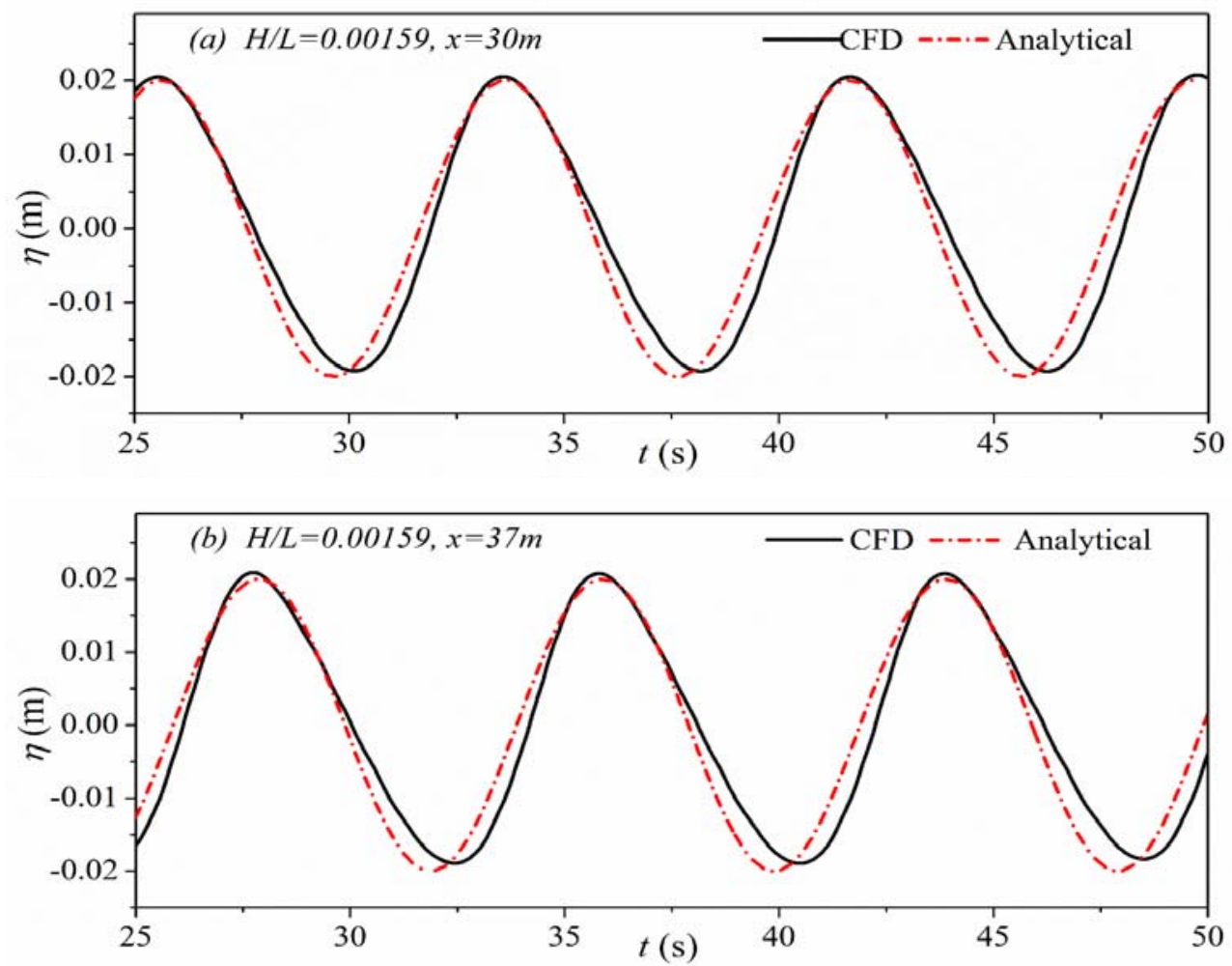


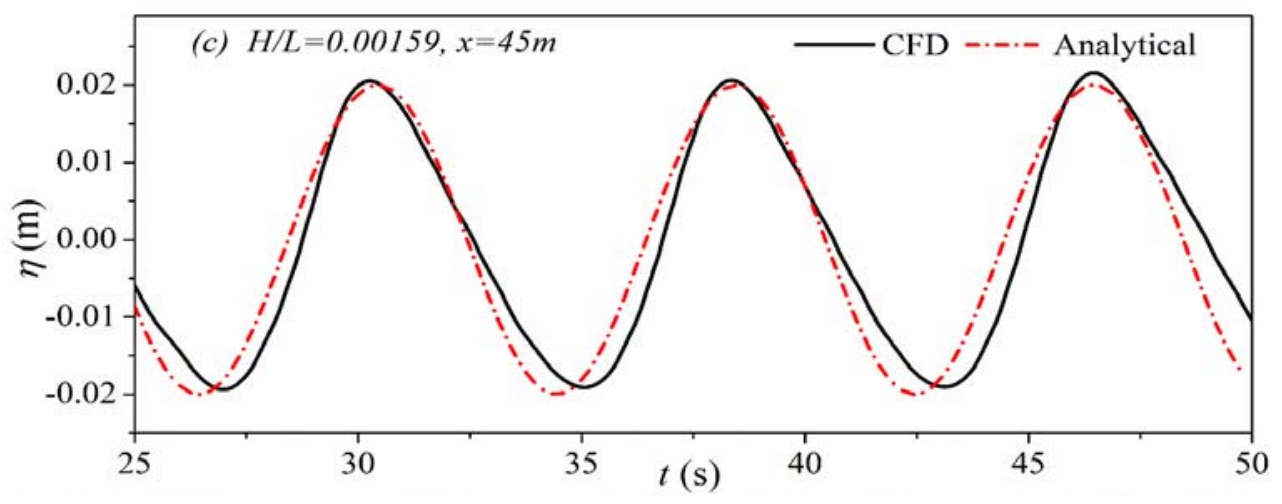

Fig 10. Surface elevation $(\eta)$ versus time for Case 4.
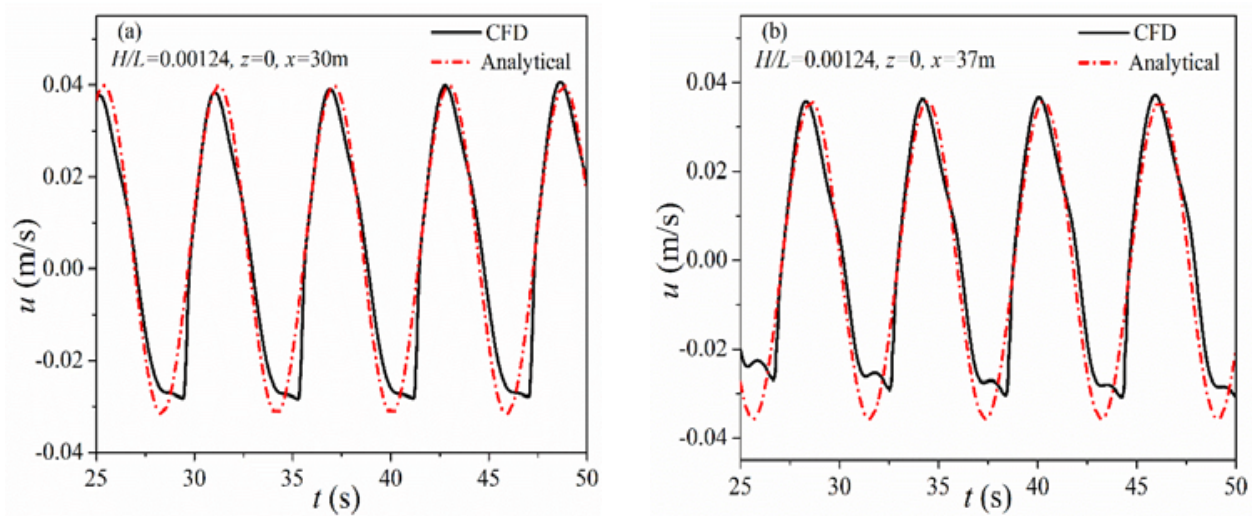

Fig. 11. Comparison of horizontal velocity $(u)$ between CFD and analytical results on the free surface $(z=0)$ at $x=30 \mathrm{~m}$ and $37 \mathrm{~m}$ for Case-1.
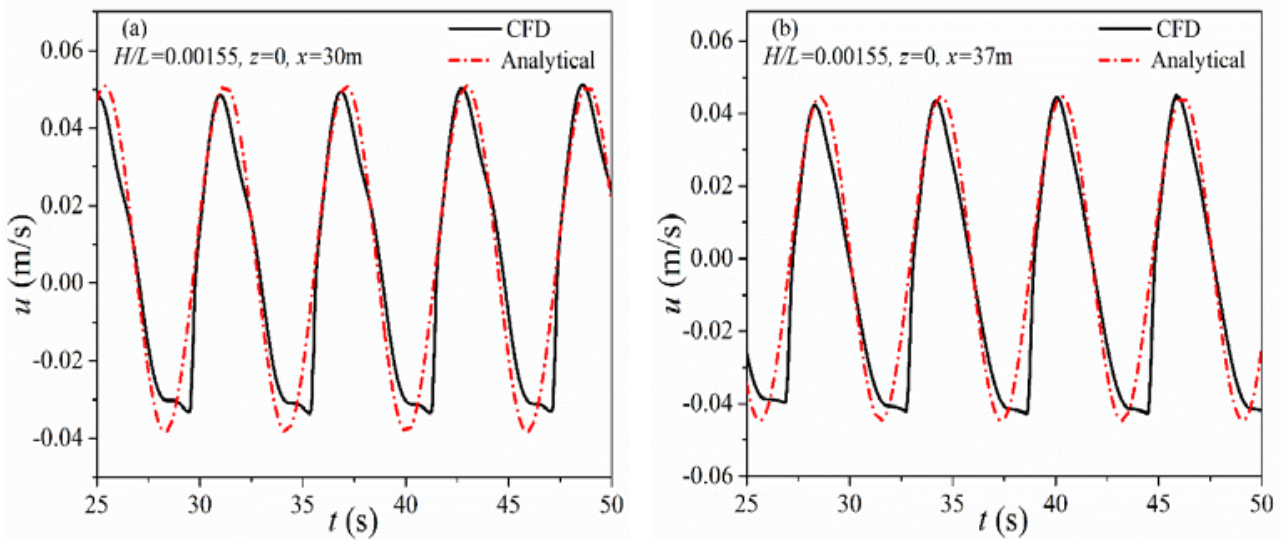

Fig. 12. Comparison of horizontal velocity $(u)$ between CFD and analytical results on the free surface $(\mathrm{z}=0)$ at $x=30 \mathrm{~m}$ and $37 \mathrm{~m}$ for the Case-2. 

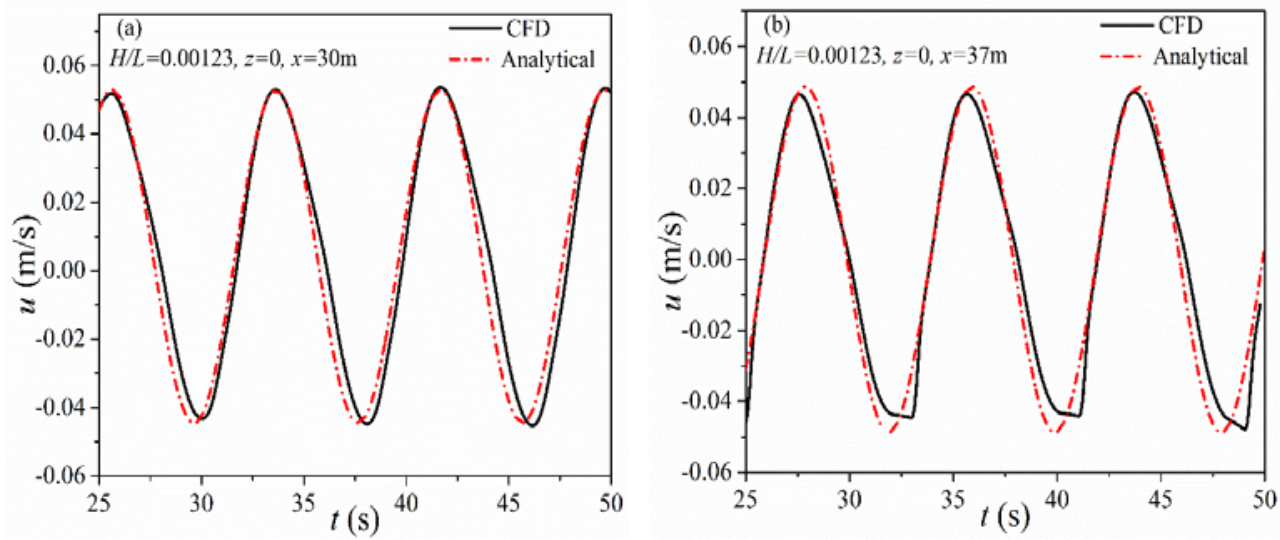

Fig. 13. Comparison of horizontal velocity $(u)$ between CFD and analytical results on the free surface $(z=0)$ at $x=30 \mathrm{~m}$ and $37 \mathrm{~m}$ for Case- 3 .
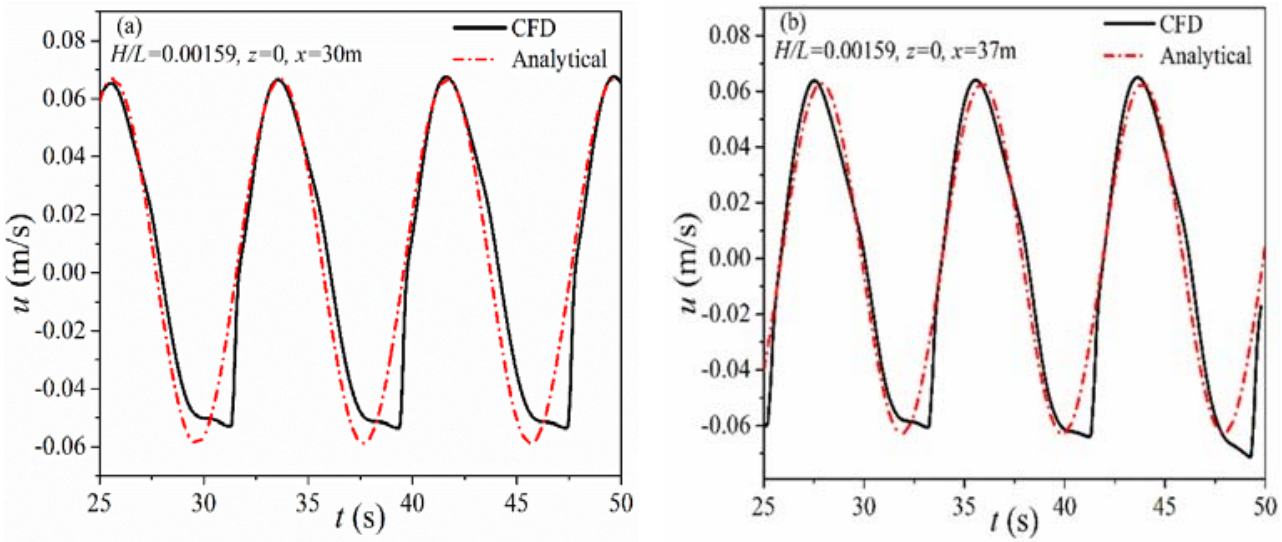

Fig. 14. Comparison of horizontal velocity $(u)$ between $C F D$ and analytical results on the free surface $(\mathrm{z}=0)$ at $x=30 \mathrm{~m}$ and $37 \mathrm{~m}$ for Case- 4 .

Linear wave theory in the viscous numerical model gives the best performance in shallow water (Le Méhauté 1976, Fig. 4) at very low wave steepness conditions $(H / L=0.00123)$.

Waves are stable $\&$ accurate at a distance of $x=30 \mathrm{~m}$, at a depth $d=1 \mathrm{~m}$, and wave height $H=0.031 \mathrm{~m}$ for Case 3.

It is also recommended that linear wave theory in shallow water can be used for investigating wavebody interactions placed at $x=30 \mathrm{~m}$ away from the inflow boundary.

The modulated wave properties fit precisely with the analytical solution at $x=30 \mathrm{~m}$ from the inflow boundary for $H / L=0.00123$ and $d=1 \mathrm{~m}$. The numerical solutions perfectly agree with the analytical solutions.

It has shown that the accuracy of the linear wave generated by the inflow method excellently matches the analytical solution at the free surface. The relative error of which is $1.43 \%$ for Case 3 .

\section{REFERENCES}

Benjamin, T. B. and M. J. Lighthill (1954). On cnoidal waves and bores. Proceedings of the Royal Society A: Mathematical, Physical and Engineering Sciences 224 (1159), 448-460.

Boussinesq, M. J. (1871). Théorie de l'intumescence liquide, appelée onde solitaire ou de translation, se propageant dans un canal rectangulaire. Comptes rendus de l'Académie des Sciences 72, 755-759.

Cornejo, P. and H. H. Sepulveda (2016). Computational fluid dynamics modelling of a midlatitude small scale upper ocean front. Journal of Applied Fluid Mechanics 9 (4), 1851-1863.

Dean, R. G. and R. A. Dalrymple (1984). Water wave mechanics for engineers and scientists. Prentice Hall, N.J.

Farhadi, A., H. Ershadi, H. Emdad and G. RadE (2016). Comparative study on the accuracy of 
S. S. Yadav and P. DebRoy / JAFM, Vol. 15, No. 2, pp. 537-549, 2022.

solitary wave generations in an ISPH- based numerical wave flume. Applied Ocean Research 54, 115-136.

Goring, D. G. (1978). Tsunamis the Propagation of Long Waves onto a Shelf. Ph.D. Thesis, California Institute of Technology, Pasadena, California.

Grilli, S. T., I. A. Svendsen and R. Subramanya (1997). Breaking criterion and characteristics for solitary waves on slopes. Journal Waterway Port Coastal Ocean Engineering 123, 102-112.

Gualtieri, C. and H. Chanson (2011). Experimental study of a positive surge. Part 2: Comparison with literature theories and unsteady flow field analysis. Environmental Fluid Mechanics 11, 641-651.

Gualtieri, C. and H. Chanson (2012). Experimental study of a positive surge. Part 1: Basic flow patterns and wave attenuation. Environmental Fluid Mechanics 12, 145-159.

Guyenne, P. and S. T. Grilli (2006). Numerical study of three dimensional overturning waves in shallow. Journal of Fluid Mechanics 547, 361388.

Hirt, C. W. and B. D. Nichols (1981). Volume of fluid (VOF) method for the dynamics of free boundaries. Journal of Computational Physics 39, 210-225.

Huang, C. J. and C. M. Dong (2001). On the interaction of a solitary wave and a submerged dike. Coastal Engineering 43 (3/4), 256-286.

Jensen, A., G. K. Pedersen and D. J. Wood (2003). An experimental study of wave run up at a steep beach. Journal of Fluid Mechanics 486, 161-188.

Keulegan, G. H. (1948). Gradual damping of solitary waves. Journal Research of the National Bureau of Standards 40, 487-498.

Lal, A. and M. Elangovan (2008). CFD simulation and validation of flap type wave maker. World Academy of Science Engineering and Technology 46, 7.

Le Mehaute, B. (1976). An introduction to hydrodynamics and water waves. Limnology and Oceanography (New York: SpringerVerlag).

Leng, X. and H. Chanson (2017). Unsteady velocity profiling in bores and positive surges. Flow Measurement and Instrumentation 54, 136145.

Leng, X., B. Simon, N. Khezri, P. Lubin and H. Chanson (2018a). CFD modeling of tidal bores: development and validation challenges. Coastal Engineering Journal 60(4), 423-436.

Leng, X., H. Chanson and D. Reungoat (2018b). Turbulence and turbulent flux events in tidal bores: case study of the undular tidal bore of the Garonne River. Environmental Fluid Mechanics 18(4), 807-828.

Li, Y. and F. Raichlen (2001). Solitary wave runup on plane slopes. Journal Waterway Port Coastal Ocean Engineering 127(1), 33-44.

Liang, X. F., J. M. Yang, J. Li, L. F. Xiao and X. Li (2010). Numerical simulation of irregular wave simulation irregular wave train. Journal of Hydrodynamics, Ser. B 22(4), 537-545.

Lin, P. and P. L. F. Liu (1998). A numerical study of breaking waves in the surf zone. Journal of Fluid Mechanics 359, 239-264.

Liu, H., W. Wu and B. L. Wang (2000). Vertical wall reflection of a fully nonlinear solitary wave. Ocean Engineering 18 (1), 1-6.

$\mathrm{Lu}, \mathrm{J}$. and X. Yu (2008). Numerical study of solitary wave fission over an underwater step. Journal of Hydrodynamics, Ser. B 20(3), 398-402.

Lynett, P. J., T. R. Wu and P. L. F. Liu (2002). Modeling wave runup with depth integrated equations. Coastal Engineering 46(2), 89-107.

Mei, C. C. (1983). The applied dynamics of ocean surface wave (World Scientfic)

Peng, QI. and H. Yijun (2006). A VOF-based numerical model for breaking waves in surf zone. Chinese Journal of Oceanology and Limnology 24(1), 57-64.

Saincher, S. and J. Banerjee (2015). Design of a numerical wave tank and wave flume for low steepness waves in deep and intermediate water. Procedia Engineering 116, 221-22.

Seiffert, B., M. Hayatdavoodi and R. C. Ertekin (2014). Experiments and computations of solitary wave forces on a coastal bridge deck Part I: flat plate. Coastal Engineering 88, 194209.

Wijetunge, J. J. (2010). Numerical simulation of the 2004 Indian ocean tsunami: case study of effect of sand dunes on the spatial distribution of inundation in hambantota, Sri Lanka. Journal of Applied Fluid Mechanics 3 (2), 125 135.

Wu, N. J., S. C. Hsiao, H. H. Chen and R. Y. Yang (2016). The study on solitary waves generated by a piston type wave maker. Ocean Engineering 117, 114-129.

Wu, N. J., T. K. Tsay and Y. Y. Chen (2014a). Generation of stable solitary waves by a piston type wave maker. Wave Motion 54(2), 240255.

Wu, Y. T. and S. C. Hsiao (2013). Propagation of solitary waves over a submerged permeable breakwater. Coastal Engineering 81, 1-18.

Wu, Y. T. and S. C. Hsiao (2017). Propagation of solitary waves over double submerged barriers. Water 9(12), 917. 
S. S. Yadav and P. DebRoy / JAFM, Vol. 15, No. 2, pp. 537-549, 2022.

Wu, Y. T., C. L. Yeh and S. C. Hsiao (2014b). Three dimensional numerical simulation on the interaction of solitary waves and porous breakwaters. Coastal Engineering 85, 12-29.

Wu, Y. T., S. C. Hsiao, Z. C. Huang and K. S. Hwang (2012). Propagation of solitary waves over a bottom mounted barrier. Coastal Engineering $62,31-47$.

Yang, W. J., T.T Zhang, C. Li, S. M. Li and X. H. $\mathrm{Xu}$ (2019). Numerical simulation of pitching sloshing under microgravity. Journal of Applied Fluid Mechanics 12 (5), 1527-1537. 